\title{
Biologia comparada e exigências térmicas de Cryptoblabes gnidiella em dieta artificial
}

\author{
Rudiney Ringenberg ${ }^{(1)}$, Marcos Botton ${ }^{(2)}$, Mauro Silveira Garcia $^{(1)} \mathrm{e}^{\text {Aline Nondillo }}{ }^{(3)}$
}

(1)Universidade Federal de Pelotas, Caixa Postal 354, CEP 96001-000 Pelotas, RS. E-mail: ringenbe@bol.com.br, msgarcia@ufpel.tche.br
(2)Embrapa Uva e Vinho, Rua Livramento, № 515, Caixa Postal 130, CEP 95700-000 Bento Gonçalves, RS. E-mail: marcos@cnpuv.embrapa.br
(3)Universidade do Vale do Rio de Sinos, Av. Unisinos, № 950, Bairro Cristo Rei, CEP 93022-000 São Leopoldo, RS. E-mail: aline@cnpuv.embrapa.br

Resumo - O objetivo deste trabalho foi avaliar o desenvolvimento de Cryptoblabes gnidiella em dietas artificiais e conhecer as exigências térmicas da espécie. A biologia do inseto foi estudada em laboratório $\left(26 \pm 1^{\circ} \mathrm{C}\right.$, umidade relativa de $70 \pm 10 \%$ e fotófase de 14 horas), em três dietas artificiais à base de feijão carioca $\left(\mathrm{D}_{1}\right)$, feijão branco e "pellet" de alfafa $\left(D_{2}\right)$ e feijão branco $\left(D_{3}\right)$. As exigências térmicas das fases de desenvolvimento foram determinadas em laboratório, tendo-se criado o inseto na $\mathrm{D}_{2}$, nas temperaturas de $18^{\circ} \mathrm{C}, 22^{\circ} \mathrm{C}, 26^{\circ} \mathrm{C}$ e $30^{\circ} \mathrm{C}$, umidade relativa de $70 \pm 10 \%$ e fotófase de 14 horas. Com base na tabela de vida de fertilidade, $\mathrm{a}_{2}$ foi a mais adequada para criação de C. gnidiella em laboratório e proporcionou uma viabilidade total de 53,30\%. A temperatura base e a constante térmica para o ciclo total (ovo-adulto) foram 12,26 ${ }^{\circ} \mathrm{C} \mathrm{e} \mathrm{569,91} \mathrm{graus-dia,} \mathrm{respec-}$ tivamente. Com base nas exigências térmicas, estimou-se que o inseto completa 3,25 gerações anuais em Caxias do Sul, RS e 9,19 em Petrolina, PE.

Termos para indexação: traça-dos-cachos, videira, temperatura base.

\section{Compared biology in artificial diets and thermal requirements of Cryptoblabes gnidiella}

\begin{abstract}
This work was conducted to evaluate the development of Cryptoblabes gnidiella in artificial diets, and to know the thermal requirements of the species. Biology was studied under laboratory conditions $\left(26 \pm 1^{\circ} \mathrm{C}\right.$, relative humity of $70 \pm 10 \%$ and $\mathrm{L} / \mathrm{D} 14: 10 \mathrm{~h})$ using three artificial diets based on bean $\left(\mathrm{D}_{1}\right)$, white bean and pellet of alfafa $\left(D_{2}\right)$ and of white bean $\left(D_{3}\right)$. Thermal requirements of honeydew moth were estimated at four constant temperatures $\left(18^{\circ} \mathrm{C}, 22^{\circ} \mathrm{C}, 26^{\circ} \mathrm{C}\right.$ e $\left.30^{\circ} \mathrm{C}\right)$ using $\mathrm{D}_{2}$ artificial diet. Based on fertility life table, $\mathrm{D}_{2}$ was the most appropriate diet to rear C. gnidiella in laboratory providing a total viability of $53.30 \%$. The lower threshold temperature and thermal requirements for the biological cycle (egg to adult) were $12.26^{\circ} \mathrm{C}$ and 569.91 day degrees, respectively. The specie completes 3.25 generations in Caxias do Sul, RS and 9.19 in Petrolina, PE.
\end{abstract}

Index terms: honeydew moth, grape, threshold temperature

\section{Introdução}

A produção de uvas no Brasil concentra-se nas regiões Sul, Sudeste e Nordeste, com destaque para os Estados do Rio Grande do Sul, São Paulo, Santa Catarina, Paraná, Pernambuco e Minas Gerais. O Estado do Rio Grande do Sul é responsável por aproximadamente 60\% da área cultivada, é o principal produtor de uvas para processamento, e o Nordeste destaca-se no cultivo para mesa (Sidra, 2004).

Com a ampliação das áreas cultivadas e a busca constante pelo incremento da qualidade das uvas, problemas anteriormente considerados de menor importância, pelos técnicos e viticultores, passaram a influir decisiva- mente na rentabilidade da atividade (Botton et al., 2003). Entre os de ordem fitossanitária, a traça-dos-cachos, Cryptoblabes gnidiella (Millière, 1867) (Lepidoptera: Pyralidae), tem se destacado por danos significativos em cachos de uvas no Rio Grande do Sul e no Vale do São Francisco, PE (Botton et al., 2003). Essa espécie pode, ainda, alimentar-se dos frutos de abacate, banana, carambola, citros, figo, kiwi, maçã, manga, mirtilo, uva, pêra e pêssego, das vagens de feijão, das "maçãs" do algodão, espigas e folhas do milho e da inflorescência do sorgo, arroz e trigo em países como Israel, Espanha, Portugal e Uruguai (Singh \& Singh, 1997).

As lagartas de C. gnidiella alojam-se no interior dos cachos ainda verdes, raspam a casca do engaço, 
o que causa a murcha e conseqüente queda das uvas (Gallo et al., 2002). Quando o ataque ocorre próximo à colheita, elas provocam o rompimento das bagas, o que resulta no extravasamento do suco sobre o qual proliferam bactérias causadoras da podridão ácida, reduzindo a qualidade dos vinhos ou depreciando os frutos para o comércio in natura (Botton et al., 2003). Além disso, em algumas situações, sobre os ferimentos causados pela alimentação do inseto pode ocorrer a proliferação de fungos como Aspergillus carbonarius, A. niger e Penicillium sp., responsáveis pela produção da ocratoxina A nos vinhos que reduz a qualidade do produto final, bem como põe em risco a saúde dos consumidores (ICV, 2004).

A traça-dos-cachos não é uma praga nova da videira no Brasil (Gallo et al., 1970), porém, não existem informações sobre a biologia da espécie, base para qualquer programa de monitoramento e controle do inseto.

O objetivo deste trabalho foi avaliar o desenvolvimento de C. gnidiella em dietas artificiais, com fontes protéicas diferentes, para criação em laboratório, bem como, determinar as exigências térmicas da espécie, estimando-se o número de gerações que o inseto realiza durante o ano, em diferentes regiões produtoras de uva.

\section{Material e Métodos}

A criação de C. gnidiella foi iniciada com lagartas coletadas em cachos de uva, em parreirais da cultivar Cabernet Sauvignon, no Município de Bento Gonçalves, RS (299'44" S, 51³1'50" O, altitude aproximada de $640 \mathrm{~m}$ ), em fevereiro de 2002. Os cachos com as lagartas foram conduzidos ao laboratório, tendo-se criado os insetos até o estágio de pupa, sobre o hospedeiro natural. Logo após, as pupas foram transferidas para placas de Petri, com uma folha de papel-filtro umedecida com água destilada até a emergência. Os adultos foram mantidos em gaiolas de PVC de $20 \mathrm{~cm}$ de diâmetro por $20 \mathrm{~cm}$ de altura, fechadas na parte superior e inferior com tela tipo tule, revestidas na parte interna com tecido preto "Lycra", utilizado como substrato para postura. Os adultos foram alimentados com mel a $10 \%$, através de rolos dentais, mantidos em recipientes de vidro com capacidade de $3 \mathrm{~mL}$, tendo-se renovado o alimento a cada dois dias. Em cada gaiola foram mantidos aproximadamente 25 casais. $\mathrm{O}$ pano preto com as posturas foi retirado a cada dois dias, e os ovos foram incubados em potes de plástico com capacidade de $300 \mathrm{~mL}$, contendo no interior papel-filtro umedecido com água destilada. Esta metodologia foi adaptada de Ascher et al. (1983).
O trabalho foi conduzido no Laboratório de Entomologia da Embrapa Uva e Vinho, em Bento Gonçalves, RS, em câmaras climatizadas (FANEM modelo 347-CDG) $\left(26 \pm 1^{\circ} \mathrm{C} ; 70 \pm 10 \%\right.$ de umidade relativa e fotófase 14 horas).

O desenvolvimento dos estágios imaturos de C. gnidiella foi avaliado em três dietas artificiais com diferentes fontes protéicas. A dieta $\mathrm{D}_{1}$ foi desenvolvida por Parra et al. (1995), para criação de Bonagota cranaodes e era composta por feijão carioca (347 g,) levedura de cerveja (52 g), ácido ascórbico (4,9 g), ácido sórbico (1,6 g), nipagin (3,3 g), tetraciclina (0,8 mg), ácido propiônico (1,2 mL), formaldeído a 38\% (3,2 mL), mistura vitamínica 40,6 mL (niacinamida, $1 \mathrm{mg}$; pantotenato de cálcio, $1 \mathrm{mg}$; tiamina, $1 \mathrm{mg}$; riboflavina, 0,25 mg; piridoxina, 0,25 mg; ácido fólico, 0,25 mg; biotina, 0,02 mg; vitamina $\mathrm{B}_{12}$, 0,002 mg; inositol, $20 \mathrm{mg}$ ), ágar (21 g) e água $(1.000 \mathrm{~mL})$. A $\mathrm{D}_{2}$ foi desenvolvida por Ascher et al. (1983) para criação de C. gnidiella, e era composta por feijão branco (330 g), levedura de cerveja (68 g), ácido ascórbico (7 g), nipagin (11 g), tetraciclina (1 g), “pellet” de alfafa (330 g), ágar (25 g) e água (1.200 mL). A $\mathrm{D}_{3}$, de Shorey \& Hale (1965) para criação de Lepidoptera, era composta por feijão branco (2.133 g), levedura de cerveja (320 g), ácido ascórbico (32 g), ácido sórbico (10 g), nipagin (20 g), formaldeído a 38\% (20 mL), ágar (128 g) e água $(6.400 \mathrm{~mL})$. O preparo dessas dietas foi realizado de acordo com Parra (2001).

Para determinação da duração e viabilidade do estágio larval, lagartas recém-eclodidas, provenientes de posturas dos adultos criados em cachos de uvas, foram colocadas uma em cada tubo de vidro $(2,5 \times 8,5 \mathrm{~cm})$ previamente esterilizados, contendo um cubo de dieta artificial com $6 \mathrm{~cm}^{3}$, tamponados com algodão hidrófobo.

Os tubos foram acondicionados em câmaras climatizadas, com acompanhamento diário do desenvolvimento até a fase adulta. As pupas foram retiradas com auxílio de pinças e transferidas, individualmente, para tubos de vidro (2,5x8,5 cm), com papel-filtro no interior, umedecido com água destilada, tamponados com algodão hidrófobo e mantidos em câmaras climatizadas.

Foram registrados a duração e a viabilidade dos estágios de ovo, lagarta e pupa, o peso de pupas com 24 horas de idade, a razão sexual, o número de ínstares, a fecundidade e a fertilidade. A separação dos sexos foi feita com base nas características morfológicas dos adultos, segundo Scatoni \& Bentancourt (1983), e a razão sexual calculada pela fórmula: $r s=n \underline{0}$ de fêmeas $/(n-0$ de fêmeas + no ${ }^{0}$ de machos). 
Para cada dieta artificial, foram individualizadas 150 lagartas. O delineamento experimental foi inteiramente casualizado, e os resultados submetidos à análise da variância, tendo-se comparado as médias pelo teste de Tukey $(\mathrm{p}<0,05)$ por meio do programa Genes (Cruz, 2001).

O número de ínstares foi determinado a partir da medição diária da cápsula cefálica de 30 lagartas, previamente separadas por dieta. As medidas foram realizadas por meio do tubo de vidro, utilizando-se a ocular micrométrica Wild MMS 235, acoplada a um microscópio estereoscópico, pelo método de distribuição de freqüências proposto por Parra \& Haddad (1989).

A fecundidade (número de ovos por fêmea) de C. gnidiella foi avaliada, tendo-se individualizado no mínimo seis casais por tratamento, em gaiolas de PVC transparentes semi-flexíveis (copos invertidos), com capacidade de $300 \mathrm{~mL}$, com um pequeno orifício tamponado com "pano preto", para servir como substrato de postura e permitir a renovação do ar. Os copos foram dispostos sobre o substrato de postura, dentro de placas de Petri com $10 \mathrm{~cm}$ de diâmetro. Os adultos foram alimentados da mesma forma que na criação de manutenção. Diariamente, foram retiradas as posturas para a contagem dos ovos. Após a contagem, eles foram incubados em tubos de vidro $(2,5 \times 8,5 \mathrm{~cm})$, fechados com filme de PVC, para avaliação da duração do período embrionário e viabilidade. Com os dados biológicos, foi calculada a tabela de vida de fertilidade para as diferentes dietas (Silveira Neto et al., 1976).

Estudou-se o desenvolvimento do inseto nas temperaturas de $18^{\circ} \mathrm{C}, 22^{\circ} \mathrm{C}, 26^{\circ} \mathrm{C}$ e $30^{\circ} \mathrm{C}$, em câmaras climatizadas. Os insetos foram provenientes da criação de manutenção conduzida sobre a dieta $\mathrm{D}_{2}$.

O estágio de ovo foi acompanhado nas respectivas temperaturas, incubando-se 100 ovos, com no máximo 12 horas de idade, dispostos em quatro repetições de 25 ovos cada, no interior de tubos de ensaio $(8,5 \times 2,5 \mathrm{~cm})$, tampados com filme de PVC, que foram colocados no interior de câmaras climatizadas. A temperatura base inferior ( $\mathrm{Tb}$ ) e a constante térmica (K) foram estimadas pelo método da hipérbole, utilizando-se o programa Mobae (Moraes et al., 1995). A duração e a viabilidade do período embrionário, nas diferentes temperaturas, foram comparadas pelo teste de Tukey $(\mathrm{p}<0,05)$ com o programa Genes (Cruz, 2001).

A determinação da Tb e da $\mathrm{K}$ dos estágios de lagarta e pupa de C. gnidiella foi realizada, individualizando-se 150 lagartas recém-eclodidas em tubos de vidro $(8,5 \times 2,5 \mathrm{~cm})$, previamente esterilizados e tamponados com algodão hidrófobo. O preparo da dieta, transferência de lagartas e cuidados assépticos foram realizados de acordo com Parra (2001). As lagartas e pupas foram criadas em câmaras climatizadas, nas mesmas condições que o estágio de ovo, até alcançarem a fase adulta. Os cálculos para estimativa da Tb, K e a comparação das médias, para os estágios de lagarta e pupa, foram idênticos aos do estágio de ovo. O número de gerações anuais para Caxias do Sul (RS) e Petrolina (PE) foi estimado com base nas exigências térmicas (Cividanes, 2000), utilizando-se as normais térmicas máxima ( $\left.\mathrm{T}_{\text {máx }}\right)$ e mínima ( $\left.\mathrm{T}_{\text {mín }}\right)$ desses municípios (Brasil, 1992). A partir dos dados biológicos, obtidos na temperatura na qual o ciclo foi completado em menor tempo $\left(30^{\circ} \mathrm{C}\right)$, estimou-se o número de gerações que C. gnidiella pode desenvolver anualmente em laboratório.

\section{Resultados e Discussão}

A duração média do estágio de lagarta, na temperatura de $26 \pm 1^{\circ} \mathrm{C}$, foi de 25,6 dias na dieta à base de feijão branco e "pellet" de alfafa $\left(\mathrm{D}_{2}\right)$, tendo sido inferior aos 28,92 e 30,82 dias observados nas dietas com feijão branco $\left(D_{3}\right)$ e carioca $\left(D_{1}\right)$ (Tabela 1$)$. Quando o inseto foi criado com grãos de milho, Swailem \& Ismail (1972) obtiveram uma duração de 13 e 16 dias, nas temperaturas de $27^{\circ} \mathrm{C}$ e $25^{\circ} \mathrm{C}$, respectivamente, inferiores às observadas neste trabalho. Com a dieta à base de feijão branco e "pellet" de alfafa, na temperatura de $25 \pm 2^{\circ} \mathrm{C}$, Ascher et al. (1983) verificaram uma duração de 21 dias, enquanto Gallo et al. (2002) relataram 25 dias, quando o inseto foi criado sobre bagas de uva.

O melhor desenvolvimento das lagartas de C. gnidiella na dieta à base de feijão branco e "pellet"

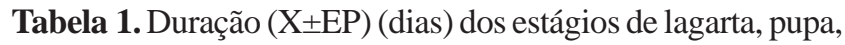
ovo e período de lagarta à emergência do adulto de Cryptoblabes gnidiella, em dietas artificiais $^{(1)}$.

\begin{tabular}{ccccc}
\hline Dieta $^{(2)}$ & Lagarta & Pupa & Ovo & Período (lagarta-adulto) \\
\hline $\mathrm{D}_{1}$ & $30,82 \pm 0,7135 \mathrm{a}$ & $8,20 \pm 0,1659 \mathrm{a}$ & $3,67 \pm 0,2108 \mathrm{a}$ & $38,82 \pm 0,8641 \mathrm{a}$ \\
& $(13-56)[98]$ & $(6-11)[89]$ & $(3-4)[80]$ & $(23,5-67,5)[77]$ \\
$\mathrm{D}_{2}$ & $25,57 \pm 0,5359 \mathrm{~b}$ & $7,22 \pm 0,1516 \mathrm{ab}$ & $3,62 \pm 0,1829 \mathrm{a}$ & $33,64 \pm 0,5673 \mathrm{~b}$ \\
& $(18-44)[96]$ & $(6-10)[84]$ & $(3-4)[170]$ & $(29,5-54,5)[81]$ \\
$\mathrm{D}_{3}$ & $28,91 \pm 1,0162 \mathrm{a}$ & $6,28 \pm 0,5441 \mathrm{~b}$ & - & $36,22 \pm 1,0705 \mathrm{a}$ \\
& $(22-37)[34]$ & $(5-11)[26]$ & & $(32,5-50,5)[26]$ \\
\hline
\end{tabular}

${ }^{(1)}$ Médias seguidas da mesma letra não diferem entre si pelo teste de Tukey a 5\% de probabilidade; valores entre parênteses indicam o intervalo de variação e aqueles entre colchetes indicam o número de observações; temperatura $26 \pm 1^{\circ} \mathrm{C}$, UR $70 \pm 10 \%$, fotófase de 14 horas. ${ }^{(2)} \mathrm{D}_{1}$ : feijão carioca; $\mathrm{D}_{2}$ : feijão branco e "pellet” de alfafa; $\mathrm{D}_{3}$ : feijão branco. (3)Adultos não fizeram posturas. 
de alfafa, quando comparado com a de feijão branco sem "pellet" de alfafa, pode estar ligado ao fato de que insetos mastigadores possuem melhor crescimento, desenvolvimento e fecundidade, quando alimentados com dietas com maior teor de nitrogênio e água (Panizzi \& Parra, 1991). Ascher et al. (1983) incorporaram "pellet” de alfafa na dieta, como fonte de $\mathrm{N}$, o que proporcionou melhor desenvolvimento ao inseto. Além disso, acredita-se que como as lagartas de C. gnidiella possuem hábito de tecer teias para se proteger, a textura da dieta com o "pellet" de alfafa permitiu utilizar este substrato também como proteção do estágio larval.

As lagartas de C. gnidiella passaram por cinco ínstares nas três dietas avaliadas. O coeficiente de determinação $\left(\mathrm{R}^{2}\right)$ foi de 1 e a razão de crescimento $(\mathrm{k})$ de 1,38, dentro dos limites de 1,1 a 1,9 propostos por Dyar (1890), o que indica que $100 \%$ dos indivíduos apresentaram cinco ínstares, independentemente da dieta fornecida. Esse número de ínstares também foi observado por Swailem \& Ismail (1972), quando criaram C. gnidiella sobre grãos de milho, e foi superior aos quatro ínstares citados por Gallo et al. (2002).

Nas dietas à base de feijão carioca, feijão branco e "pellet" de alfafa e feijão branco, o período pupal médio na temperatura de $26 \pm 1^{\circ} \mathrm{C}$ foi de $8,20,7,22$ e 6,28 dias, respectivamente. Diferença significativa foi verificada entre a $D_{1}$ e a $D_{3}$ (Tabela 1). Swailem \& Ismail (1972) observaram, para este estágio, sete $\left(27^{\circ} \mathrm{C}\right)$ e 10 dias $\left(25^{\circ} \mathrm{C}\right)$.

A duração média do período lagarta-adulto, na temperatura de $26 \pm 1^{\circ} \mathrm{C}$, foi menor (33,64 dias) na dieta à base de feijão branco e "pellet" de alfafa $\left(\mathrm{D}_{2}\right)$, e as demais não diferiram entre si (Tabela 1). Esse resultado é semelhante ao apresentado por Gallo et al. (2002), que relataram uma duração média, do período lagartaadulto, de 32 dias sobre bagas de uva. Swailem \& Ismail (1972) observaram duração média de $20\left(27^{\circ} \mathrm{C}\right)$ e 25 dias $\left(25^{\circ} \mathrm{C}\right)$ sobre grãos de milho.
A duração média do período embrionário, semelhante nas dietas à base de feijão carioca e branco com "pellet” de alfafa, foi de 3,67 e 3,62 dias, respectivamente, na temperatura de $26 \pm 1^{\circ} \mathrm{C}$ (Tabela 1). Swailem \& Ismail (1972) verificaram que quando os ovos foram incubados à temperatura de $27^{\circ} \mathrm{C}$, o período embrionário médio foi de três dias, enquanto que Gallo et al. (2002) relataram quatro dias.

$\mathrm{O}$ peso médio das pupas, na dieta à base de feijão carioca, foi de 8,10 mg e 9,10 mg, respectivamente, para machos e fêmeas, e foi semelhante ao observado na dieta à base de feijão branco, 7,50 mg para machos e 8,50 mg para fêmeas. O maior peso médio foi observado na dieta à base de feijão branco e "pellet" de alfafa, $10 \mathrm{mg}$ e 10,70 mg para machos e fêmeas, respectivamente, o que ratifica a melhor adequação nutricional desse alimento para a criação de C. gnidiella (Tabela 2). Segundo Panizzi \& Parra (1991), um peso reduzido de pupas é resultado da inadequação das dietas para alimentação das lagartas, o que tem influência direta na capacidade reprodutiva dos adultos.

A viabilidade do estágio de lagarta foi semelhante nas dietas à base de feijão carioca e feijão branco e "pellet" de alfafa, com valores de 68\% e 64\%, respectivamente, enquanto na dieta com feijão branco foi de $22,67 \%$, significativamente inferior às demais dietas (Tabela 2). No estágio de pupa, a viabilidade foi maior na dieta à base de feijão branco $(86,21 \%)$, enquanto que na de feijão carioca e feijão branco com "pellet” de alfafa foi de $78,78 \%$ e $85,11 \%$, respectivamente, não tendo havido diferenças entre as últimas (Tabela 2). Para o estágio de ovo, a viabilidade foi de $80,87 \%$ na dieta à base de feijão carioca e 85,26\% na de feijão branco e "pellet" de alfafa (Tabela 2). O parâmetro não pôde ser avaliado na dieta à base de feijão branco, porque os adultos não fizeram postura.

Tabela 2. Viabilidade (\%) dos estágios de lagarta, pupa e ovo e período de lagarta à emergência de adulto, razão sexual e peso de pupas (X土EP) de Cryptoblabes gnidiella em dietas artificiais ${ }^{(1)}$.

\begin{tabular}{|c|c|c|c|c|c|c|c|}
\hline \multirow[t]{2}{*}{ Dieta $^{(2)}$} & \multirow[t]{2}{*}{ Lagarta } & \multirow[t]{2}{*}{ Pupa } & \multirow[t]{2}{*}{ Ovo } & \multirow[t]{2}{*}{ Ciclo total } & \multirow[t]{2}{*}{ Razão sexual } & \multicolumn{2}{|c|}{ Peso de pupas (mg) } \\
\hline & & & & & & Macho & Fêmea \\
\hline $\mathrm{D}_{1}$ & $\begin{array}{c}68,00 \pm 3,8215 a \\
(150)\end{array}$ & $\begin{array}{c}78,78 \pm 4,1296 a \\
(94)\end{array}$ & $\begin{array}{c}80,87 \pm 5,7122 a \\
(80)\end{array}$ & $\begin{array}{c}51,99 \pm 0,0599 a \\
(150)\end{array}$ & $\begin{array}{l}0,38 \\
(78)\end{array}$ & $\begin{array}{c}8,10 \pm 0,2 b \\
(48)\end{array}$ & $\begin{array}{c}9,10 \pm 0,4 \mathrm{~b} \\
(29)\end{array}$ \\
\hline $\mathrm{D}_{2}$ & $\begin{array}{c}64,00 \pm 3,9323 a \\
(150)\end{array}$ & $\begin{array}{c}85,11 \pm 3,6918 \mathrm{a} \\
(90)\end{array}$ & $\begin{array}{c}85,26 \pm 6,3205 a \\
(170)\end{array}$ & $\begin{array}{c}53,33 \pm 0,0703 a \\
(150)\end{array}$ & $\begin{array}{l}0,49 \\
(81)\end{array}$ & $\begin{array}{c}10,00 \pm 0,2 \mathrm{a} \\
(42)\end{array}$ & $\begin{array}{c}10,70 \pm 0,3 \mathrm{a} \\
\text { (39) }\end{array}$ \\
\hline $\mathrm{D}_{3}$ & $\begin{array}{c}22,67 \pm 3,4299 b \\
(150)\end{array}$ & $\begin{array}{c}86,21 \pm 6,5166 b \\
(29)\end{array}$ & $-{ }^{(3)}$ & $\begin{array}{c}16,67 \pm 0,2103 b \\
(150)\end{array}$ & $\begin{array}{l}0,50 \\
(26)\end{array}$ & $\begin{array}{c}7,50 \pm 0,4 \mathrm{~b} \\
(13)\end{array}$ & $\begin{array}{c}8,50 \pm 0,6 \mathrm{~b} \\
(13)\end{array}$ \\
\hline
\end{tabular}

(1)Médias seguidas da mesma letra, na coluna, não diferem entre si pelo teste de Tukey a 5\% de probabilidade; valores entre parênteses indicam o número de observações; temperatura $26 \pm 1^{\circ} \mathrm{C}$, UR $70 \pm 10 \%$, fotófase de 14 horas. ${ }^{(2)} \mathrm{D}_{1}$ : feijão carioca; $\mathrm{D}_{2}$ : feijão branco e “pellet” de alfafa; $\mathrm{D}_{3}$ : feijão branco. ${ }^{(3)}$ Adultos não fizeram posturas. 
A viabilidade total (período lagarta-adulto), nas três dietas, foi inferior aos 75\% preconizados por Singh (1983), para que uma dieta seja considerada balanceada e adequada à criação de insetos em laboratório. Enquanto não se consegue desenvolver uma dieta mais adequada do que essa à base de feijão branco e "pellet" de alfafa, considera-se que a viabilidade obtida (53,33\%) permite manter uma criação do inseto em laboratório, de forma contínua.

$\mathrm{O}$ número de fêmeas foi menor na dieta à base de feijão carioca, tendo-se observado um desvio na proporção dos sexos, com mais machos do que fêmeas (Tabela 2). Na dieta à base de feijão branco e "pellet" de alfafa e feijão branco, o número de fêmeas foi igual ao de machos (Tabela 2). Swailem \& Ismail (1972) também encontraram razão sexual de 0,50 , quando criaram o inseto sobre grãos de milho. O menor número de fêmeas, observado na dieta à base de feijão carioca, provavelmente, deve-se à pouca adequação dessa dieta para alimentação das fêmeas (Tabela 2). Segundo Slansky \& Scriber (1985), em virtude da atividade reprodutiva, as fêmeas são mais exigentes quanto à qualidade do alimento, o que resulta em maior mortalidade dessas fêmeas, quando o substrato de criação não é adequado.

A fecundidade diária de $C$. gnidiella não apresentou diferença significativa entre as dietas à base de feijão carioca (14 ovos/fêmea) e com feijão branco e "pellet" de alfafa (20,16 ovos/fêmea). A fecundidade total na dieta à base de feijão carioca (57,70 ovos/fêmea) diferiu, significativamente, da registrada na dieta à base feijão branco e "pellet" de alfafa (105,31 ovos/fêmea). As fêmeas não ovipositaram, quando mantidas na dieta com feijão branco, o que indica que essa dieta é inadequada para a criação de C. gnidiella. A fecundidade total observada por Avidov \& Gothilf (1960) foi de 150 ovos por fêmea, em média, enquanto que Swailem \& Ismail (1972) obtiveram uma fecundidade média total de 43 ovos por fêmea. $\mathrm{O}$ emprego de grãos de milho como alimento para lagartas de C. gnidiella, conforme o trabalho de Swailem \& Ismail (1972), seria uma alternativa para a criação do inseto, porém, a baixa fecundidade dos adultos, em comparação com a dieta à base de feijão branco e "pellet" de alfafa, limita o emprego desse grão como substrato alimentar.

A duração média de uma geração de $C$. gnidiella, calculada mediante os dados da tabela de vida de fertilidade, variou em função da dieta utilizada, tendo sido de 43 dias na de feijão branco e "pellet” de alfafa e 51 dias na de feijão carioca (Tabela 3).
A taxa líquida de reprodução $\mathrm{R}_{0}$, número de vezes em que a população aumenta a cada geração, também apresentou diferença em função da dieta, que na de feijão carioca foi 2,3 vezes menor do que na de feijão branco e "pellet” de alfafa (Tabela 3).

A razão infinitesimal de aumento populacional (rm) foi 0,04456 na dieta de feijão carioca e 0,07219 na de feijão branco e "pellet” de alfafa (Tabela 3). A razão finita de aumento $(\lambda)$, que representa o número de fêmeas adicionadas à população, por fêmea numa unidade de tempo, foi maior na dieta à base de feijão branco e "pellet” de alfafa (Tabela 3).

Considerando-se a tabela de vida de fertilidade como um critério de avaliação do desempenho de uma dieta para a criação de insetos, observa-se que a dieta à base de feijão branco e "pellet" de alfafa $\left(\mathrm{D}_{2}\right)$ foi a melhor, pois proporcionou a menor duração de desenvolvimento (T), a maior viabilidade total (Tabela 2) e a maior razão finita de aumento (Tabela 3).

O tempo para desenvolvimento de $C$. gnidiella de ovo a adulto foi dependente da temperatura, tendo ocorrido diferenças significativas na duração de todos os estágios. A duração do período ovo-adulto decresceu com o aumento da temperatura, variou, em média, de 93,01 a 31,93 dias, à temperatura de $18^{\circ} \mathrm{C}$ a $30^{\circ} \mathrm{C}$, respectivamente. Esses valores foram próximos aos obtidos por Avidov \& Gothilf (1960), que observaram 32,5 e 23,5 dias nas temperaturas de $26^{\circ} \mathrm{C}$ e $29^{\circ} \mathrm{C}$, respectivamente. Segundo os autores, a viabilidade foi baixa em todas as temperaturas, verificando-se que os insetos tiveram melhor desenvolvimento nas temperaturas de $26^{\circ} \mathrm{C}$ e $30^{\circ} \mathrm{C}$.

O limite inferior de desenvolvimento ( $\mathrm{Tb}$ ) para o estágio de ovo foi de $11,97^{\circ} \mathrm{C}$ e a constante térmica (K) de 52,19 graus-dia (GD) (Tabela 4). Para esse estágio, Avidov \& Gothilf (1960) encontraram uma Tb de $13,70^{\circ} \mathrm{C}$ e K de 46,30 GD.

Tabela 3. Tabela de vida de fertilidade de Cryptoblabes gnidiella, criada em dietas artificiais, onde T é a duração média de uma geração, $\mathrm{R}_{0}$ é a taxa líquida de reprodução, $\mathrm{Rm}$ é a razão infinitesimal de aumento e $\lambda$ é a razão finita de aumento ${ }^{(1)}$.

\begin{tabular}{lcccc}
\hline Dieta $^{(2)}$ & $\mathrm{T}$ (dias) & $\mathrm{R}_{0}$ & $\mathrm{Rm}$ & $\lambda$ \\
\hline $\mathrm{D}_{1}$ & 51,01 & 9,71 & 0,04456 & 1,04556 \\
$\mathrm{D}_{2}$ & 43,00 & 22,29 & 0,07219 & 1,07486 \\
$\mathrm{D}_{3}$ & $-(3)$ & - & - & - \\
\hline
\end{tabular}

(1)Temperatura $26 \pm 1^{\circ} \mathrm{C}$, UR $70 \pm 11 \%$ e fotófase de 14 horas; iniciou-se a avaliação com 150 lagartas recém-eclodidas. ${ }^{(2)} \mathrm{D}_{1}$ : feijão carioca; $\mathrm{D}_{2}$ : feijão branco e "pellet" de alfafa; $\mathrm{D}_{3}$ : feijão branco. ${ }^{(3)} \mathrm{A}$ tabela de vida não foi calculada, pois os adultos não fizeram postura. 
A Tb para o estágio de lagarta e a $\mathrm{K}$ foram de $13,40^{\circ} \mathrm{C}$ e 383,26 GD, respectivamente, enquanto que a Tb para o estágio de pupa foi de $10,36^{\circ} \mathrm{C}$ e a $\mathrm{K}$ de $116,14 \mathrm{GD}$ (Tabela 4). O estágio de pupa, por possuir a menor Tb, parece ser o período de desenvolvimento do inseto mais tolerante à baixa temperatura.

Não foi possível comparar o limiar térmico inferior de desenvolvimento e a constante térmica dos estágios de lagarta e pupa, com os do estudo realizado por Avidov \& Gothilf (1960). Esses autores não separaram esses estágios, tendo obtido uma $\mathrm{Tb}$ de $12,7^{\circ} \mathrm{C}$ e uma constante térmica de 454,5 GD para o período lagarta-pupa.

A Tb e a K do ciclo total (ovo-adulto) foram, respectivamente, de $12,26^{\circ} \mathrm{C}$ e 569,91 GD (Tabela 4). Avidov \& Gothilf (1960) encontraram uma $\mathrm{Tb}$ de $13^{\circ} \mathrm{C}$ e uma constante térmica de $500 \mathrm{GD}$, quando criaram o inseto sobre cachos de uva, valores próximos aos obtidos neste trabalho.

Foi estimada a ocorrência de 3,25 e 9,19 gerações anuais de C. gnidiella, respectivamente, nos municípios de Caxias do Sul (RS) e Petrolina (PE), importantes pólos produtores de uva do Brasil, enquanto que em laboratório, à temperatura de $30^{\circ} \mathrm{C}$, é possível obter-se até 11,36 gerações por ano. No Uruguai, onde a temperatura é semelhante à do Sul do Brasil, Scatoni \& Bentancourt (1983) relatam a ocorrência de três gerações anuais na cultura da videira. Em Israel, C. gnidiella apresenta cinco gerações anuais sobre o abacateiro (Yehuda et al., 1991) e três sobre citrus, manga e videira (Hashem et al., 1997). Em Tuscan, na Itália, Bagnoli \& Lucchi (2001) relatam a ocorrência de três a quatro gerações anuais sobre a cultura da videira. A ocorrência de um maior número de gerações durante o ano, em Petrolina, quando comparada à de Caxias do Sul, indica que a espécie apresenta maior potencial para causar danos na região Nordeste do que nos parreirais localizados no Sul do Brasil. Esses dados corroboram

Tabela 4. Exigências térmicas de Cryptoblabes gnidiella criada em dieta artificial, em que Tb é a temperatura base inferior, $\mathrm{K}$ é a constante térmica e $\mathrm{R}^{2}$ é o coeficiente de determinação dos períodos de desenvolvimento do inseto ${ }^{(1)}$.

\begin{tabular}{lcrrc}
\hline Período & $\mathrm{Tb}\left({ }^{\circ} \mathrm{C}\right)$ & $\mathrm{K}(\mathrm{GD})$ & $\mathrm{R}^{2}$ & $\chi^{2}$ \\
\hline Ovo & 11,97 & 52,19 & 98,34 & $0,0589^{\mathrm{ns}}$ \\
Lagarta & 13,40 & 383,26 & 98,85 & $1,2950^{\mathrm{ns}}$ \\
Pupal & 10,36 & 116,14 & 98,92 & $0,0648^{\mathrm{ns}}$ \\
Ovo-adulto & 12,26 & 569,91 & 99,21 & $0,7294^{\mathrm{ns}}$ \\
\hline
\end{tabular}

(1) Temperaturas de $18^{\circ} \mathrm{C}, 22^{\circ} \mathrm{C}, 26^{\circ} \mathrm{C}$ e $30^{\circ} \mathrm{C}$; UR $70 \pm 10 \%$ e fotófase de 14 horas; iniciou-se a avaliação com 150 lagartas recém-eclodidas, em

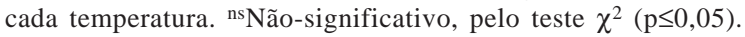

as informações, colhidas junto a produtores, de que a videira cultivada na região Nordeste do Brasil tem sido mais afetada por C. gnidiella. Por isso, trabalhos complementares devem ser conduzidos, a fim de se associarem os dados de flutuação populacional dos adultos, em armadilhas de feromônio sexual, com as exigências térmicas. $\mathrm{O}$ emprego de graus-dia, associado a informações da flutuação populacional da praga, pode auxiliar os produtores na tomada de decisão sobre a aplicação de inseticidas para o controle do inseto; essas informações, entretanto, necessitam ainda ser geradas, para o manejo da traça-dos-cachos na cultura da videira.

\section{Conclusões}

1. A dieta à base de feijão branco e "pellet" de alfafa é mais adequada para criação de Cryptoblabes gnidiella.

2. A temperatura base e a constante térmica para o ciclo total (ovo-adulto) de C. gnidiella são de $12,26^{\circ} \mathrm{C}$ e 569,91 GD, respectivamente.

3. Estima-se que C. gnidiella completa três e nove gerações anuais nos municípios de Caxias do Sul (RS) e Petrolina (PE), respectivamente.

\section{Agradecimentos}

À Coordenação de Aperfeiçoamento de Pessoal de Nível Superior (Capes), pela concessão de bolsa de estudo a Rudiney Ringenberg; à Fundação de Amparo à Pesquisa do Rio Grande do Sul (Fapergs), pela concessão de bolsa a Aline Nondillo.

\section{Referências}

ASCHER, K.R.S.; ELIYAHU, M.; GUREVITZ, E.; RENNEH, S. Rearing the honeydew moth, Cryptoblabes gnidiella, and the effect of diflubenzuron on its eggs. Phytoparasitica, v.11, p.195-198, 1983. AVIDOV, Z.; GOTHILF, S. Observations on the honeydew moth (Cryptoblabes gnidiella) in Israel. I. Biology, phenology and economic importance. Israel Journal of Agricultural Research, v.10, p.109-124, 1960.

BAGNOLI, B.; LUCCHI, A. Bionomics of C. gnidiella (Millière) (Pyralidae: Phycitinae) in Tuscan vineyards. Bulletin OILB SROP, v.24, p.79-83, 2001.

BOTTON, M.; AFONSO, A.P.S.; RINGENBERG, R. Manejo de pragas na cultura da videira. In: SEMINÁRIO ESTADUAL DE FRUTICUlTURA, 3., 2003, Palmas, PR. Anais. Palmas, PR: Facipal; Bento Gonçalves: Embrapa Uva e Vinho, 2003. p.23-31. 
BRASIL. Ministério da Agricultura e Reforma Agrária. Secretaria Nacional de Irrigação. Departamento Nacional de Meteorologia. Normais climatológicas (1961-1990). Brasília, 1992. 84p.

CIVIDANES, F.J. Uso de graus-dia em entomologia, com particular referência ao controle de percevejos pragas da soja. Jaboticabal: Funep, 2000. 31p.

CRUZ, C.D. Programa genes: aplicativo computacional em genética e estatística. Viçosa: UFV, 2001. 648p.

DYAR, H.G. The number of molts of Lepidopterous larvae. Psyche, v.5, p.420-422, 1890

GALLO, D.; NAKANO, O.; SILVEIRA NETO, S.; CARVALHO, R.P.L.; BAPTISTA, G.C.; BERTI-FILHO, E.; PARRA, J.R.P.; ZUCCHI, R.A.; ALVES, S.B.; VENDRAMIM, J.D.; MARCHINI, L.C.; LOPES, J.R.S.; OMOTO, C. Entomologia agrícola. 3.ed. Piracicaba, SP: Agronômica Ceres, 2002. 920p.

GALLO, D.; NAKANO, O.; WIENDL, F.M.; SILVEIRA NETO, S.; CARVALHO, R.P.L. Manual de entomologia agrícola. Piracicaba, SP: Agronômica Ceres, 1970. 858p.

HASHEM, A.G.; TADROS, A.W.; ABO SHEASHA, M.A. Monitoring the honeydew moth, Cryptoblabes gnidiella Mill. in citrus, mango and grapevine orchards (Lepidoptera: Pyralidae). Annals of Agricultural Science, v.42, p.335-343, 1997.

ICV. Institut Coopératif du Vin. Ochratoxin A in wines: current knowledge. Disponível em: <http://www.icv.fr>. Acesso em: jun. 2004.

MILLIÈRE, P. Iconographie et description de chenilles et de Lépidoptères inédits. Lyon: Société Linnenne de Lyon, 1867. 3v.

MORAES, R.C.B.; HADDAD, M.L.; PARRA, J.L.P. Modelos bioestatísticos aplicados à entomologia: versão 1.0. Piracicaba, SP: Universidade de São Paulo; Escola Superior de Agricultura Luiz de Queiroz, 1995. 44p.

PANIZZI, A.R.; PARRA, J.R.P. Ecologia nutricional de insetos e suas implicações no manejo de pragas. São Paulo: Manole, 1991. 359p.

PARRA, J.R.P. Técnicas de criação de insetos para programas de controle biológico. 6.ed. Piracicaba: Fealq, 2001. 134p.

PARRA, J.R.P.; EIRAS, A.E.; HADDAD, M.L.; VILELA, E.F.; KOVALESKI, A. Técnica de criação de Phtheocroa cranaodes
Meyrick (Lepidoptera: Tortricidae) em dieta artificial. Revista Brasileira de Biologia, v.55, p.537-543, 1995.

PARRA, J.R.P.; HADDAD, M.L. Determinação do número de ínstares de insetos. Piracicaba: Fealq, 1989. 49p.

SCATONI, I.B.; BENTANCOURT, C.M. Cryptoblabes gnidiella (Millière): una nueva lagarta de los racimos en los viñedos de nuestro país. Revista de la AIA, v.1, p.266-268, 1983.

SHOREY, H.H.; HALE, R.L. Mass-rearing of the larvae of nine noctuid species on a simple artificial medium. Journal of Economic Entomology, v.58, p.522-524, 1965.

SIDRA. Banco de dados agregados. Sistema IBGE de recuperação automática. Disponível em: <http://www.sidra.ibge.gov.br/>. Acesso em: $1^{\text {o }}$ jun. 2004.

SILVEIRA NETO, S.; NAKANO, O.; BARBIN, D.; VILLA NOVA, N. Manual de ecologia dos insetos. São Paulo: Agronômica Ceres, 1976. 419p.

SINGH, P. A general purpose laboratory diet mixture for rearing insects. Insect Science and Its Application, v.4, p.357-362, 1983.

SINGH, Y.P.; SINGH, D.K. Host plants, extent of damage and seasonal abundance of earhead caterpillar, Cryptoblabes gnidiella Miller. Advances in Agricultural Research in India, v.7, p.133137, 1997.

SLANSKY, J.F.; SCRIBER, J.M. Food consumption and utilization. In: KERKUT, G.A.; GILBERT, L.I. (Ed.). Comprehensive insect physiology biochemistry and pharmacology. Oxford: Pergamom, 1985. v.4, p.87-163.

SWAILEM, S.M.; ISMAIL, I.I. On the biology of the honeydew moth C. gnidiella, Millière. Bulletin de la Société Entomologique d'Egypte, v.56, p.127-134, 1972.

YEHUDA, S.B.; WYSOKI, M.; ROSEN, D. Phenology of honeydew moth, Cryptoblabes gnidiella (Millière) (Lepidoptera: Pyralidae), on avocados in Israel. Israel Journal of Entomology, v.25-26, p.149-160, 1991.

Recebido em 5 de outubro de 2004 e aprovado em 12 de abril de 2005 